\title{
Ensinar a produzir textos depois de alfabetizar: desafios e possibilidades
}

\section{Teaching to produce texts after literacy: challenges and opportunities}

Sílvia Regina Robles Juhas é especialista em docência da Língua Portuguesa pelo ISE Vera Cruz, é psicopedagoga e fonoaudióloga. Atua como formadora de professores das redes pública e particular.

Contato: sjuhas27@gmail.com

\section{Resumo}

Este artigo apresenta os resultados obtidos em uma investigação acerca da representação de professores de $3^{\circ}$ ano do ensino fundamental sobre o que sabem os alunos a respeito da produção de textos e o que ainda precisam aprender sobre o tema. Para tanto, foram analisados textos produzidos por estudantes do final do $2^{\circ}$ ano do ensino fundamental, avaliando-se também a leitura que deles fazem os professores. 0 trabalho conclui que faltam aos professores conhecimentos sobre o funcionamento da língua para que possam melhor dimensionar o ensino da produção de textos e sugere que tais conteúdos sejam desenvolvidos em cursos de formação inicial e continuada.

Palavras-chave: produção de texto; expectativas de aprendizagem; tópicos de ensino.

\section{Abstract}

This paper presents the study results obtained in a research on the representation of teachers of $3^{\text {rd }}$ year (elementary school) about what students know about text composition and what they still need to learn about the topic. It examines texts produced by students at the end of the $2^{\text {nd }}$ year (elementary school) and evaluates analyzes made by 
teachers on the same texts. The study concludes that many teachers lack knowledge of the workings of language and suggests that these skills are taught in continuing education courses.

Keywords: text production; learning expectations; topics of instruction.

\section{Introdução}

Tenho trabalhado na área da educação por mais de 20 anos, sempre com o primeiro segmento do ensino fundamental. Ao longo desse tempo, minha atuação esteve voltada à formação de professores, seja como fonoaudióloga, coordenadora pedagógica ou supervisora.

Em determinado momento de minha carreira, convivi com professores e partilhei de suas angústias ao deixarem o porto seguro que representava a cartilha e a alfabetização por meio das famílias silábicas em direção a mares nunca dantes navegados. Estudei com eles os novos referenciais teóricos, participei de cursos, aprendi a analisar as escritas das crianças e, a partir delas, a compreender com qual hipótese acerca do sistema de escrita alfabética operavam e quais desafios deveriam ser propostos para que pudessem avançar.

Foram anos de estudo dedicados a entender os processos pelos quais os alunos passam na construção da leitura e da escrita, bem como as implicações metodológicas que essa escolha teórica determina aos educadores. Assim, durante os encontros de formação, fui observando que, no que se refere à alfabetização, os professores apropriavam-se da teoria, reconheciam as hipóteses com as quais os alunos operavam e identificavam boas práticas. Essa constatação trouxe novas questões e inquietudes que deram origem ao presente trabalho.

\subsection{Meu aluno já é alfabético. E agora?}

Nesse percurso, acompanhando professores das séries iniciais do ensino fundamental, tenho notado que a maioria consegue analisar, sem maiores problemas, as escritas de seus alunos durante o processo de construção da base alfabética. Com frequência, tais professores identificam as hipóteses com as quais os alunos operam e boa parte deles é capaz de identificar também 
os conhecimentos que os alunos já possuem sobre o sistema de escrita alfabética, assim como os conteúdos que devem ser trabalhados para oportunizar sua ampliação.

Porém, após a alfabetização, como ampliar e consolidar as aprendizagens adquiridas? A partir dos vários estudos desenvolvidos durante o curso de especialização em docência em língua portuguesa, especialmente o que tematizou a construção dos processos de produção escrita e autoria, comecei a refletir sobre essa questão e a buscar respostas que pudessem orientar não apenas meu trabalho de conclusão de curso, mas também minha prática como formadora de professores.

\subsection{Dados da realidade brasileira}

Nas últimas três décadas, o Brasil passou a elaborar e aplicar avaliações de larga escala com o objetivo de estabelecer indicadores para a educação básica brasileira. A primeira edição do Sistema de Avaliação da Educação Básica (SAEB), iniciativa pioneira de avaliação em escala nacional, ocorreu em 1990. Em 2005, criou-se a Prova Brasil, que, com caráter censitário, avalia todos os estudantes da rede pública urbana de $5^{\circ}$ e $9^{\circ}$ anos do ensino fundamental (antigas $4^{a}$ e $8^{a}$ séries). Outro indicador foi implementado em 2001 pelo Instituto Paulo Montenegro e pela ONG Ação Educativa. Trata-se do Indicador do Alfabetismo Nacional (INAF), cujo objetivo é medir o índice de alfabetismo dos brasileiros de 14 a 65 anos que estejam ou não frequentando a escola.

Os dados do Relatório INAF Brasil - 2009 mostraram que $97,9 \%$ das crianças entre 7 e 14 anos estão na escola, havendo, portanto, uma quase universalização das matrículas em nosso país. Ainda segundo esse relatório, o índice de analfabetismo - que corresponde à condição dos que não são capazes de ler palavras e frases - é de $7 \%$ e vem decrescendo a cada ano. No entanto, quase metade da população $(47 \%)$ tem apenas um nível básico de alfabetismo, pois lê textos de média extensão, localiza informações e realiza pequenas inferências.

Todos os resultados de indicadores educacionais nacionais e internacionais apontam para a necessidade de uma melhoria urgente na qualidade da educação oferecida em nosso país. Boa parte dos alunos brasileiros deixa a escola após anos de estudo, sem as competências de linguagem necessárias para viabilizar seu desenvolvimento pessoal e profissional. 
O Estudo longitudinal sobre qualidade e eficácia no ensino fundamental brasileiro: GERES 2005, planejado, coordenado e executado por profissionais de seis universidades brasileiras, focalizou as aprendizagens na primeira etapa do ensino fundamental. Durante quatro anos (de 2005 a 2008), mais de 20.000 alunos de 303 escolas públicas e privadas de cinco grandes cidades brasileiras foram acompanhados por meio de avaliações periódicas que, utilizando a teoria de resposta ao item (TRI, ${ }^{1}$ buscaram medir a proficiência em língua portuguesa e matemática.

Em reportagem publicada em 11 de janeiro de 2010 no jornal Folha de São Paulo, uma das coordenadoras do GERES e pesquisadora da PUC-Rio afirmou:

\footnotetext{
O problema não estava nessa fase inicial [na alfabetização]. Nossa hipótese é que esteja na consolidação. Em vez de reforçar a leitura e interpretação de texto, muitos professores podem estar partindo para etapas seguintes, como o ensino de normas gramaticais. (Góls, 2010)
}

A análise dos resultados das avaliações nacionais e a leitura dos relatórios publicados pelo GERES ratificaram minha percepção empírica de que as questões relacionadas à alfabetização e à construção do sistema de escrita alfabética estavam, de certo modo, resolvidas para os professores alfabetizadores. Por outro lado, as questões relativas à consolidação das aprendizagens adquiridas nesse período e ao prosseguimento do trabalho em direção ao desenvolvimento da competência leitora e escritora dos alunos ainda necessitariam ser estudadas, esclarecidas e explicitadas, principalmente com os professores do $3^{\circ}$ ano do ensino fundamental, série que sucede o período alfabetizador.

Essas reflexões e constatações fizeram emergir três questionamentos, aos quais procurei responder a partir da pesquisa realizada:

- Que representações os professores de $3^{\circ}$ ano têm sobre o conhecimento de seus alunos a respeito da produção de textos?

- Quais expectativas de aprendizagem podem orientar esse ensino?

Que tópicos de formação podem ser selecionados para os professores desse ano?
1. A TRI consiste em um conjunto de modelos matemáticos que procuram representar a probabilidade de um indivíduo dar certa resposta a um item. Ela permite a comparação entre populações, desde que submetidas a provas compostas por alguns itens comuns. É a metodologia usada em avaliações de larga escala no Brasil. 


\subsection{A investigação}

Para responder a essas questões e investigar como os professores identificavam as aprendizagens dos alunos quanto à produção de texto e quais conteúdos selecionavam para consolidar e ampliar essas aprendizagens, foram analisadas produções escritas de alunos do final do $2^{\circ}$ ano do ensino fundamental de uma escola de Osasco, São Paulo. A escola atende alunos de população economicamente desfavorecida, sendo administrada por uma fundação sem fins lucrativos que oferece escolaridade gratuita aos estudantes.

Solicitou-se à professora de classe que realizasse com os alunos a reprodução de um conto maravilhoso, gênero trabalhado sistematicamente em sala. Reproduzir histórias conhecidas, conforme afirma Nóbrega (2000), possibilita a ampliação do repertório e dos recursos de textualidade, principalmente para escritores iniciantes. Em sua dissertação de mestrado, a autora afirma:

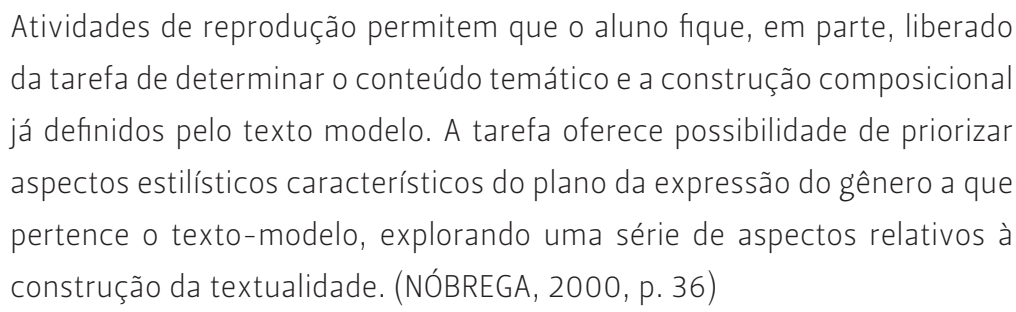

Os contos, principalmente os maravilhosos, costumam fazer parte do cotidiano das crianças, mesmo em famílias de baixo grau de letramento. Foi por tal razão e pelo fato de serem especialmente trabalhados no material didático adotado nesse ano escolar que escolhemos o gênero para a realização do trabalho.

Deixamos a critério da professora a escolha do conto, que serviria como uma referência para a reprodução, recomendando somente que ele fosse lido e discutido com os alunos de forma que eles se apropriassem do enredo, do plano do conteúdo, restandoIhes apenas a tarefa de tomar decisões quanto ao plano da forma.

A professora nos relatou que leu algumas versões do conto escolhido e selecionou uma delas para servir de referência para a reprodução. Antes de pedir aos alunos que escrevessem o texto, ela retomou a história, deixou que eles a recontassem e depois solicitou que a escrevessem. Os estudantes não tiveram acesso ao texto escrito, apenas à sua leitura. A professora não fez intervenções ou qualquer revisão nos textos produzidos pelos 
alunos. Das produções colhidas, foram selecionadas seis que, de acordo com nossa avaliação, representam a variedade das reproduções feitas pela classe. A seleção permitiu uma análise mais detalhada dos textos produzidos, tanto pela pesquisadora, quanto pelos professores que participaram da pesquisa.

\section{Fundamentação teórica}

Muito se tem estudado e discutido sobre a aquisição do sistema de escrita alfabética e a alfabetização, principalmente a partir da pesquisa de Emilia Ferreiro e Ana Teberosky realizada na década de 1970 e amplamente conhecida no meio educacional brasileiro.

A construção da escrita, nessa perspectiva, seria o resultado da combinação de vivências externas e de processos internos de assimilação. Segundo as pesquisadoras, para aprender a ler e a escrever, a criança deve atribuir sentido, interpretar os escritos que a cercam e, além disso, compreender a relação entre as letras e os sons da língua.

Em seus estudos, Ferreiro e Teberosky (1985) identificaram hipóteses com as quais as crianças operam no decorrer do processo de construção da escrita. Atualmente, boa parte dos professores alfabetizadores, apoiada nas descobertas dessas pesquisadoras, é capaz de identificar essas hipóteses nas escritas produzidas por seus alunos. Da mesma forma, o tratamento didático e metodológico nessa etapa de escolaridade, que geralmente ocorre nos dois primeiros anos do ensino fundamental, parece ser, ao menos no plano das intenções e do discurso, conhecido pelos professores que atuam nos anos iniciais de aprendizagem da escrita.

À medida que se discutia sobre a alfabetização e as possíveis metodologias que deveriam ser construídas para atender a esses novos referenciais teóricos, outra questão começou a emergir: a de que não bastava aprender a ler e a escrever, mas era preciso adquirir competência para usar a leitura e a escrita.

De acordo com Soares (2000), a diferença entre ser alfabetizado e ser letrado reside no fato de que o primeiro é o sujeito que sabe ler e escrever, ao passo que o segundo é aquele que faz uso da leitura e da escrita de forma frequente e competente; é o sujeito que adquire uma nova condição.

Socialmente e culturalmente, a pessoa letrada já não é a mesma coisa que era quando analfabeta ou iletrada, ela passa a ter uma 
outra condição social e cultural - não se trata de mudar de nível ou de classe social, cultural, mas de mudar seu lugar social, seu modo de viver na sociedade, sua inserção na cultura - sua relação com os outros, com o contexto, com os bens culturais torna-se diferente. (SOARES, 2000, p. 37)

Se apenas saber ler e escrever não é suficiente para interagir e participar de uma sociedade que exige, cada vez mais, múltiplas competências dos sujeitos que nela estão inseridos, e se esses aprendizados ocorrem majoritariamente na escola, como garantir que os alunos sigam aprendendo e desenvolvendo competências linguísticas que lhes permitam usar a linguagem em diferentes circunstâncias, de diferentes formas, todas elas adequadas às exigências impostas pela situação comunicativa?

Uma das soluções possíveis para tal questão é proporcionar que os estudantes vivenciem, no ambiente escolar, situações comunicativas mais próximas possíveis das que viverão fora da escola, de modo que os textos lidos e produzidos na aula sejam muito similares aos lidos e escritos fora dela. Para atender a essa premissa, é fundamental o desenvolvimento de um trabalho que contemple a diversidade de gêneros textuais.

Marcuschi (2002, p. 22-23) define g'ênero textual como "textos materializados que encontramos em nossas vidas e que apresentam características sócio-comunicativas definidas por conteúdo, propriedades funcionais, estilo e composição característica". Adotar essa concepção no ensino escolar pressupõe ensinar aos estudantes que, mais do que conteúdos escolares, os gêneros textuais são ferramentas de apropriação da língua e de inserção nas atividades de comunicação dentro e fora da escola. Beth Brait (2005, p. 158), ao escrever sobre os conceitos bakhtinianos, explica:

Os gêneros discursivos concebidos como uso com finalidades comunicativas e expressivas não é ação deliberada, mas deve ser dimensionado como manifestação da cultura. Nesse sentido, não é espécie e nem tampouco modalidade de composição: é dispositivo de organização, troca, divulgação, armazenamento e, sobretudo, de criação de mensagens em contextos culturais específicos. Afinal, antes mesmo de se configurar como terreno de produção de mensagens, os gêneros são elos de uma cadeia que não apenas une como também dinamiza as relações entre as pessoas ou sistemas de linguagens e não apenas entre interlocutor e receptor.

Se os gêneros são, de certa forma, a materialidade dos discursos proferidos e os elos da cadeia discursiva, quanto mais bem 
compreendidos eles forem por aqueles que os utilizam, maiores serão as chances de proporcionarem a seus usuários eficácia e eficiência em situações comunicativas nas quais participem. Conhecer e compreender os gêneros implica levar em conta o contexto em que são produzidos, isto é, os interlocutores, a esfera de circulação e até mesmo os suportes. Implica também conhecer a estrutura composicional característica, a forma como são organizados e o arcabouço sobre o qual são construídos.

Bronckart (2007) assume o posicionamento teórico de Adam e defende as sequências textuais como unidades estruturais relativamente estáveis que integram e organizam a macroestrutura do texto. 0 autor descreve cinco sequências: a narrativa, a descritiva, a argumentativa, a explicativa e a dialogal. Um texto seria, então, a combinação e a articulação de diferentes tipos de sequência.

Por fim, mas não por último, conhecer e compreender os gêneros implica a identificação e a seleção dos recursos que a língua oferece para tornar esses gêneros dizíveis: recursos de coerência e coesão, responsáveis por constituir o texto um todo, por tecer uma trama a partir de diferentes elementos que tornarão o discurso mais compreensível, tanto do ponto de vista semântico, quanto do ponto de vista sintático.

Todos os aspectos até aqui relacionados podem e devem tornarse objeto de ensino numa escola preocupada em oferecer a seus alunos não apenas conteúdos escolares, mas também condições de inserção num mundo altamente letrado, como o que vivemos na atualidade.

Para desenvolver o ensino a partir do pressuposto teórico de que os textos participam de práticas sociais e de que é no uso que se moldam os gêneros de texto com os quais nossa cultura se alimenta, precisamos compreender como a língua se materializa para dar origem aos textos. Ou seja, necessitamos conhecer as condições de textualidade que contribuem para a composição dos textos no que diz respeito à leitura e à própria produção. Neste estudo, iremos restringir-nos à abordagem de questões relacionadas à produção de textos escritos. 


\section{Análise do conto de referência}

Os contos estão profundamente ligados às origens históricas e culturais e ao contexto social das comunidades em que circulam. Compreender essa ligação permite que se identifique a universalidade dos temas, mesmo diante de adaptações realizadas para atender às especificidades de tempo e lugar.

Por tal razão, escolhemos para este trabalho a reprodução de um dos mais conhecidos contos maravilhosos. Pretendíamos, assim, garantir que os alunos tivessem conhecimento do enredo para que pudéssemos observar os recursos de textualização que seriam utilizados na reprodução.

Antes de nos debruçarmos sobre os textos que os alunos produziram, realizamos uma análise do texto tomado como referência - retirado do livro Chapeuzinho Vermelho e outras histórias, da coleção Fábulas de Ouro - buscando identificar o enredo, as características do gênero, a construção composicional e os recursos coesivos e estilísticos nele presentes. 0 objetivo da análise foi explicitar as características textuais para tentar identificá-las nos textos produzidos pelos alunos, de forma a reconhecer os conhecimentos que eles já tinham sobre a produção escrita do gênero e aqueles que precisariam aprender.

\subsection{Conteúdo temático e construção composicional}

A versão do conto Chapeuzinho Vermelho utilizada como base para a reprodução é uma tradução feita a partir do italiano. Para construí-la, o autor pautou-se em versões que apresentavam um final feliz. Nesta, Chapeuzinho e sua avó são salvas da barriga do lobo por um corajoso caçador que acidentalmente encontra 0 malvado dormindo após devorá-las.

Nos contos, assim como ocorre no texto escolhido para a atividade, o conteúdo narrado se estrutura predominantemente em sequências narrativas (ADAM, 1992 apud BRONCKART, 2007). Tal estrutura, compreendida e reconhecida como típica desse gênero de texto, sustenta o enredo, na medida em que organiza uma sucessão de fatos ocorridos em determinado tempo e espaço, de modo a formar um todo coerente e coeso.

De acordo com Bronckart (2007), o estudo da sequência narrativa tem longa história, sendo suas características descritas e analisadas por diferentes correntes teóricas. 0 autor afirma 
que só se pode falar em sequência narrativa quando a organização dos acontecimentos da história resultar em um todo, "uma ação completa, com início, meio e fim" (BRONCKART, 2007, p. 220).

No texto tomado como referência para a reprodução, identificamos as fases descritas por Bronckart, as quais são apresentadas a seguir.

\begin{tabular}{|c|c|}
\hline $\begin{array}{l}\text { 1. Fase da } \\
\text { situação } \\
\text { inicial }\end{array}$ & $\begin{array}{l}\text { Certa manhã, sua mãe foi até o portão do jardim e chamou: } \\
\text { - Chapeuzinho, leve este cestinho de pães para sua avozinha que está } \\
\text { doente. Mas cuidado! Vá pela trilha do bosque, e não fique parando. Assim } \\
\text { você evita encontros perigosos. } \\
\text { Chapeuzinho Vermelho, depois de beijar a mãe, saiu depressa, dizendo: - } \\
\text { Não se preocupe! Irei correndo até chegar à casa da vovó! Prometo que não } \\
\text { vou parar nenhuma vez! } \\
\text { Cheia de boas intenções, a menina dirigiu-se para o bosque, mas pouco } \\
\text { depois, o conselho da mãe não passava de uma fraca lembrança. } \\
\text { - Que belos morangos! Como são vermelhos... } \\
\text { Deixando o cestinho no chão, Chapeuzinho Vermelho inclinou-se sobre o } \\
\text { arbusto. } \\
\text { - Como estão maduros! Nossa, que grandes! Hum! Que delícia! Só mais } \\
\text { um! Este é o último!... mais este.... Hum! } \\
\text { Entre folhas e árvores, as frutinhas vermelhas destacavam-se } \\
\text { convidativas e a menina corria daqui e dali com a boca cheia dos deliciosos } \\
\text { morangos. De repente lembrou-se da mãe, de sua promessa, da avozinha e } \\
\text { do cestinho... Virou-se aflita e procurou a trilha. Que alívio! } 0 \text { cestinho ainda } \\
\text { estava lá. Chapeuzinho Vermelho, cantarolando, retomou o seu caminho. } \\
\text { Andou, andou, pelo bosque, que ficava cada vez mais denso. } \\
\text { Uma grande borboleta amarela apareceu iluminada por um raio de sol } \\
\text { filtrado entre as árvores. } \\
\text { Chapeuzinho Vermelho correu em sua direção. } \\
\text { - Vou pegar você! Vou pegar você... - ela gritava perseguindo a borboleta } \\
\text { até avistar, no meio dos arbustos, grandes margaridas. } \\
\text { - Como são lindas! - exclamou a menina e, lembrando-se da avozinha, } \\
\text { começou a colher as flores para fazer um belo ramalhete. }\end{array}$ \\
\hline $\begin{array}{l}\text { 2. Fase da } \\
\text { complicação }\end{array}$ & $\begin{array}{l}\text { Mas dois terríveis olhos a espiavam por detrás das árvores... } \\
\text { O coração de Chapeuzinho Vermelho começou a bater forte quando ouviu } \\
\text { um estranho barulho. } \\
\text { - Preciso voltar para o meu caminho e ir bem depressa! - disse a garota } \\
\text { assustada. } \\
\text { Chegou finalmente à estradinha que havia deixado para colher flores, mas } \\
\text { novamente seu coração saltou ao ouvir um vozeirão perguntando: } \\
\text { - Aonde você vai, linda menina, assim sozinha no bosque? } \\
\text { - Vou visitar minha vovozinha e levar estes pães doces para ela. Vovó está } \\
\text { doente e me espera em sua casinha, que fica atrás das árvores, no fim desta } \\
\text { trilha! - respondeu Chapeuzinho Vermelho com um fio de voz. } \\
\text { - Sua vovozinha mora sozinha? } \\
\text { - Sim, e não abre a porta para nenhum desconhecido! } \\
\text { O lobo astuto tramou um plano e, enquanto engolia saliva, se despediu: } \\
\text { - Até logo, espero encontrar você novamente! }\end{array}$ \\
\hline
\end{tabular}


continua...

\begin{tabular}{|c|c|}
\hline & $\begin{array}{l}\text { Começou a correr pela estradinha, com suas longas patas. } \\
\text { Enquanto corria com a língua de fora, um pouco pelo cansaço, mas } \\
\text { também por estar com água na boca, o lobo pensava: } \\
\text { - Primeiro devoro a vovozinha e, depois, espero a netinha! } \\
\text { Finalmente avistou a pequena casa que procurava. } \\
\text { - TOC! TOC! - bateu à porta. } \\
\text { Procurando afinar o mais possível seu vozeirão, a fera respondeu: } \\
\text { - Sou eu, Chapeuzinho Vermelho. Vim Ihe trazer pãezinhos doces, pois a } \\
\text { senhora está doente! } \\
\text { - Pode entrar! - disse a vovozinha sem suspeitar de nada. } \\
\text { Uma sombra assustadora já aparecia na parede... } \\
\text { Pobre vovozinha! O lobo mau havia entrado. Com uma só bocada devorou } \\
\text { a indefesa senhora! } \\
\text { Mais tarde Chapeuzinho Vermelho também bateu à porta da casinha. } \\
\text { - Vovozinha, posso entrar?! - perguntou a garota. } \\
\text { O lobo, vestido com a toca e o xale da avó, estava deitado na cama. } \\
\text { Tentando imitar uma voz delicada, respondeu: } \\
\text { - Claro, pode vir! } \\
\text { - Vovó, a senhora está com uma voz tão grossa! - disse a menina } \\
\text { espantada. } \\
\text { - É para cumprimentar melhor você - respondeu o lobo. } \\
\text { - Mas que olhos grandes a senhora tem! } \\
\text { - É para ver você melhor! } \\
\text { - Suas mãos estão tão grandes! - exclamou Chapeuzinho Vermelho, } \\
\text { aproximando-se da cama. } \\
\text { - São para acariciar melhor você - respondeu o lobo. } \\
\text { - Que bocão a senhora tem! - murmurou com um fio de voz a pequena, } \\
\text { muito espantada. } \\
\text { - É para devorar melhor você! - rugiu o lobo. E, pulando da cama com } \\
\text { um grande salto, devorou num segundo Chapeuzinho Vermelho. Logo depois, } \\
\text { bastante satisfeito, adormeceu profundamente. }\end{array}$ \\
\hline & $\begin{array}{l}\text { Enquanto isso, um caçador estava no bosque avistou a casinha. Pensou } \\
\text { em parar ali e pedir pouso. Afinal, estava cansado, pois vinha perseguindo um } \\
\text { grande lobo mau, que assustava toda a vizinhança. Ele havia perdido o rastro } \\
\text { do animal. De repente, um estranho ronco vindo da casinha fez com que o } \\
\text { caçador, desconfiado, olhasse pela janela... } \\
\quad \text {... e ele viu o lobo que, com a barriga estufada, dormia na cama da vovó, } \\
\text { depois de sua lauta refeição. } \\
\text { - O lobo?! Desta vez ele não me escapa! } \\
\text { Lentamente, sem fazer barulho, o caçador carregou sua espingarda } \\
\text { e abriu a janela devagarinho. Apontou o cano da arma bem na cabeça do } \\
\text { monstro... e BUM!! o lobo estava morto! } \\
\text { - Finalmente peguei você! - gritou feliz o caçador. - Não fará mal a } \\
\text { ninguém! } \\
\text { Depois pegou o seu facão e abriu a barriga do lobo. Qual não foi sua } \\
\text { surpresa ao ver sair daquele barrigão Chapeuzinho Vermelho e sua avozinha. } \\
\text { Estavam salvas! }\end{array}$ \\
\hline $\begin{array}{l}\text { 5. Fase da } \\
\text { situação } \\
\text { final }\end{array}$ & $\begin{array}{l}\text { - Chegou bem a tempo! - murmurou a pobre velhinha atordoada de tanta } \\
\text { emoção. } \\
\text { - Agora pode voltar tranquilamente para sua casa, o lobo mau está morto! } \\
\text { - disse o caçador para Chapeuzinho Vermelho. }\end{array}$ \\
\hline
\end{tabular}

continua... 
continua...

6. Fase da - Mas nunca se esqueça de que a trilha é o caminho mais seguro! moral

Quadro 1 - Fases da narrativa no conto Chapeuzinho Vermelho

Conforme demonstrado no quadro 1, é possível encontrar na versão tomada como referência as cinco fases principais da narrativa.

Segundo Bronckart (2007), na fase da situação inicial, o estado inicial é apresentado ao leitor. Esse estado representa um equilíbrio que será transformado pelo desencadear da narrativa. Na versão utilizada, há uma concentração na fase inicial da caracterização da personagem: Chapeuzinho é apresentada como uma menina que se encanta e se diverte com flores, morangos e borboletas. 0 autor parece pretender que o leitor construa a imagem da personagem como dispersiva, ingênua e infantil, e não como apenas uma menina desobediente que ignora o conselho da mãe.

As escolhas lexicais realizadas criam um clima leve, de tranquilidade. As descrições, as adjetivações e o uso de interjeições para caracterizar os espaços, bem como as percepções e reações da personagem - por exemplo: "Como estão maduros! Nossa, que grandes! Hum! Que delícia!" - funcionam como pano de fundo para estabelecer o contraste que virá a seguir. Isso nos leva a pensar que, mesmo sendo secundária, a sequência descritiva não é dispensável nesse conto.

Após essa fase inicial, segue-se a fase da complicação, em que acontecem as perturbações que desequilibrarão a situação inicial. No caso dessa versão, os elementos "dois terríveis olhos" e "um vozeirão" introduziram um corte no lirismo inicial para desencadear uma nova ordem nos acontecimentos.

Ao introduzir uma sequência dialogal entre a menina e o lobo, o autor evidencia sua intenção de produzir um efeito no plano enunciativo. Suas escolhas lexicais estão a serviço da construção do clima de desequilíbrio e da introdução da tensão; "seu coração saltou" ou, ainda, "respondeu Chapeuzinho Vermelho com um fio de voz" são exemplos da mudança no estado de espírito da menina em relação à fase inicial. Essas escolhas marcam o estilo do autor e explicitam suas possíveis intenções em provocar, no leitor, a mesma tensão da personagem.

Complicação estabelecida, chega-se à fase das ações, a qual, de 
acordo com Bronckart (2007, p. 220), "reúne os acontecimentos desencadeados pela perturbação". Como o próprio nome diz, essa é a parte da narrativa em que ações acontecem e em que o autor busca aproximar o leitor da trama e torná-la mais ágil.

Na versão analisada, um recurso utilizado para destacar os fatos em contraposição ao plano de fundo foi a alternância dos tempos verbais: do pretérito imperfeito (em "corria" e "pensava") para o presente (em "devoro" e "espero") e para o pretérito perfeito (em "avistou" e "bateu"). No tópico seguinte, quando abordarmos os recursos estilísticos, essa questão será retomada de maneira mais detalhada.

A introdução de nova sequência dialogal entre a netinha e o lobo travestido de avó foi a estratégia mobilizada para agilizar a narrativa, produzindo a sensação de que a sucessão de fatos está acontecendo diante do leitor. A utilização do discurso direto estabelece uma dinâmica de leitura que induz à percepção do ritmo em que ocorrem as ações. A alternância dos turnos e 0 estabelecimento de pares adjacentes do tipo pergunta/resposta imprimiram a essa fase a agilidade e o suspense necessários para 0 encaminhamento em direção ao clímax do conto.

O suspense pode ser evidenciado pela qualificação da palavra dita por cada personagem em contraste com as características de sua personalidade. Essa qualificação deu-se por meio das escolhas relativas ao modo de dizer na sequência dialogal, como nos seguintes exemplos: "procurando afinar o mais possível seu vozeirão, a fera respondeu"; "tentando imitar uma voz delicada, respondeu [o lobo]"; e "murmurou com um fio de voz [Chapeuzinho]".

As qualificações das personagens e do cenário onde as ações aconteceram são outros fatores que contribuem para a construção do suspense e da tensão característicos dessa fase da narrativa, conforme se pode observar em: "uma sombra assustadora já aparecia na parede"; "o lobo, vestido com a toca e o xale da avó, estava deitado na cama".

A fase seguinte, denominada fase da resolução, "introduz os acontecimentos que levam a redução da tensão" (BRONCKART, 2007, p. 220). Aqui também foi utilizada a alternância dos tempos verbais: pretérito imperfeito para marcar o pano de fundo ("vinha perseguindo um grande lobo mau, que assustava toda a vizinhança") e perfeito para as ações que levaram à resolução ("pegou o seu facão e abriu a barriga do lobo"). 
Encontramos também nessa fase descrições que detalham as ações da personagem e estimulam a imaginação do leitor, por exemplo: "Lentamente, sem fazer barulho, o caçador carregou sua espingarda e abriu a janela devagarinho". Tais descrições parecem constituir-se em marca do estilo do autor, sempre preocupado em envolver o leitor com a trama, fazendo-o experienciar as vivências das personagens.

A quinta fase da narrativa é intitulada fase da situação final. É aquela na qual se obtém um novo estado de equilíbrio por meio da resolução da complicação. Nesse conto, tal momento coincide com a tranquilidade da avó e da neta diante da morte do antagonista, o lobo, o que garantiria à menina um retorno tranquilo e sem perigos à sua casa.

Na versão analisada, encontramos ainda a fase da moral, em que o caçador aconselha a menina de que "nunca se esqueça de que a trilha é o caminho mais seguro". A presença dessa fase está diretamente ligada ao posicionamento adotado pelo autor e, conforme afirma Bronckart (2007, p. 221), "explicita a significação global atribuída à história".

\subsection{Recursos estilísticos}

Um texto é muito mais do que a reunião de frases e palavras. Para que as frases reunidas se constituam efetivamente em um texto, faz-se necessário estabelecer relações de sentido por meio de diferentes recursos semânticos e sintáticos.

Ao considerar o destinatário e selecionar o gênero mais adequado à situação comunicativa, o autor deve procurar mobilizar os recursos estilísticos mais apropriados ao gênero selecionado, assim como - principalmente no caso dos gêneros literários - seu estilo individual, fruto de sua experiência e de seu conhecimento da língua.

Para explicitar o que denominou estilo, Bakhtin (1997, p. 284) afirma:

O estilo é indissociavelmente vinculado a unidades temáticas determinadas e, o que é particularmente importante, a unidades composicionais: tipo de estruturação e de conclusão de um todo, tipo de relação entre o locutor e os outros parceiros da comunicação verbal (relação com o ouvinte, ou com o leitor, com o interlocutor, com o discurso do outro, etc.). 0 estilo entra como elemento na unidade de gênero de um enunciado: os estilos da líng’ua pertencem por natureza ao gênero. 
$\mathrm{Na}$ análise que se segue, procuramos identificar alguns dos recursos estilísticos utilizados no texto aqui tomado como referência.

Koch (1991, p. 19) afirma que "o conceito de coesão textual diz respeito a todos os processos de sequencialização que asseguram (ou tornam recuperável) uma ligação linguística significativa entre os elementos que ocorrem na superfície textual". A autora propõe a existência de duas modalidades de coesão: a coesão referencial, responsável pela manutenção do tema, pela referenciação e pela remissão, e a coesão sequencial, responsável por fazer o texto progredir.

Examinamos os principais mecanismos de coesão empregados na versão do conto utilizada para a reprodução. Para identificar os mecanismos de coesão referencial, mapeamos a cadeia coesiva das personagens principais: a menina e o lobo.

O mapeamento da cadeia coesiva de Chapeuzinho Vermelho revelou que poucas foram as substituições realizadas ao longo do texto, tendo o autor optado, na maior parte das vezes, por repetir a expressão nominal Chapeuzinho Vermelho para referirse à personagem. Tal expressão foi substituída apenas por nomes genéricos (menina, garota), por outra expressão nominal (linda menina) e pelo pronome pessoal (ela), quando em situação de calma, ou ainda por garota assustada, menina espantada e a pequena, quando em situação de desequilíbrio diante da ameaça do lobo.

Ao analisarmos a cadeia coesiva do lobo, foi possível verificar como essa personagem é introduzida a partir de metonímias (terríveis olhos e um vozeirão), para somente depois ser recuperado por expressões nominais ou nomes genéricos, como lobo astuto, fera, lobo mau, o lobo e o monstro. Nesse caso, a manutenção por meio da constituição de um campo lexical garantiu a continuidade semântica na caracterização do lobo.

A coesão sequencial responsável pela progressão textual se dá por meio de diferentes mecanismos, tanto de sequenciação parafrástica, em que se utilizam procedimentos de recorrência, quanto de sequenciação frástica, sem procedimentos de recorrência estrita $(\mathrm{KOCH}, 1991)$.

Entre os mecanismos de sequenciação parafrástica, podemos destacar a utilização de diferentes tempos verbais, tais como: 0 pretérito imperfeito, tempo usado para comentar ("uma casinha branca onde morava") e o perfeito, usado para narrar as ações das personagens ("Chapeuzinho Vermelho, depois de beijar a mãe, saiu 
depressa"). Essa utilização de diferentes tempos verbais diferencia as ações colocadas em primeiro plano, os processos dinâmicos relacionados às personagens centrais ("chegou finalmente à estradinha"; "o lobo astuto tramou um plano"), das ações postas em segundo plano na história ("uma casinha branca onde morava uma linda garota"; "frutinhas vermelhas destacavam-se convidativas").

0 pretérito imperfeito, tempo utilizado no segundo plano da narrativa, tem como característica marcar ocorrências num passado não pontual, em que as ações costumavam acontecer por determinado tempo (era, vivia, pensava). Em contraposição a ele há o pretérito perfeito, um passado pontual que marca as ações que acabaram de ocorrer, permitindo registrar uma sucessão de acontecimentos que começam e terminam uns após os outros; por exemplo, "chegou finalmente à estradinha [...], mas novamente seu coração saltou".

Outro mecanismo de coesão parafrástica identificado no texto foi o paralelismo sintático, que pode ser observado no diálogo entre a menina e o lobo disfarçado de avó:

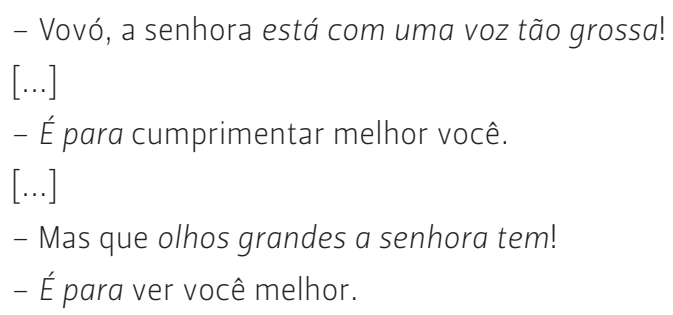

Esse recurso de utilização da mesma estrutura sintática, preenchida com itens lexicais diferentes $(\mathrm{KOCH}, 1991)$, deu a agilidade ao texto, ampliou o suspense a cada resposta e precedeu o desfecho, momento em que a menina é devorada pelo lobo.

Quanto aos mecanismos de sequenciação frástica, responsáveis pela manutenção do tema e pelo estabelecimento de relações entre os segmentos do texto, podemos destacar o uso de articuladores textuais que marcam a passagem do tempo (certa manhã, pouco depois) durante a ação dos personagens.

Para garantir a sequenciação do texto e evitar lacunas que interfeririam na compreensão, o autor lançou mão de recursos que garantiram a progressão temática. Entre eles está a progressão com tema constante, como se pode observar no trecho em que a menina está no bosque e diferentes enunciados se sucedem para descrever suas ações e seus sentimentos: "- Que belos morangos! 
Como são vermelhos... - Deixando de lado o cestinho no chão, Chapeuzinho Vermelho inclinou-se sobre o arbusto".

Outro recurso utilizado foi a progressão temática linear, na qual a articulação entre tema (elemento sobre o qual se vai dizer alguma coisa) e rema (aquilo que se diz a respeito do tema) transforma o rema de um enunciado no tema do enunciado seguinte (KOCH; ELIAS, 2009):

\begin{tabular}{|c|c|}
\hline TEMAS & REMAS \\
\hline$[\ldots]$ no meio de um espesso bosque & {$[$ havia $]$ uma casinha branca } \\
\hline$[$ nessa casinha branca] onde & morava uma linda garota. \\
\hline
\end{tabular}

0 autor também estabelece o encadeamento das ações da personagem Chapeuzinho Vermelho e de seu antagonista, o lobo, por meio de conectores: "O coração de Chapeuzinho Vermelho começou a bater mais forte quando ouviu um estranho barulho".

O emprego desses recursos de manutenção e progressão temática tem por finalidade facilitar a interpretação e a construção da coerência pelo leitor. 0 cuidado em garantir a progressão temática ao produzir um texto evita saltos temáticos, os quais podem ser decorrentes da não clareza do autor sobre os processos de escrita. Escrever pressupõe comunicar um enunciado a um interlocutor ausente e, por essa razão, é fundamental a antecipação de possíveis dúvidas ou espaços de incerteza que o leitor deverá preencher durante a leitura.

Ao procurarmos identificá-los no texto de referência e depois reconhecer quais são utilizados ou não nas reproduções dos alunos, poderemos ter indicações de possíveis tópicos de ensino.

\section{Os textos produzidos por estudantes recém-alfabetizados}

Procuramos realizar nas reproduções dos alunos as mesmas análises feitas no texto de referência. Observamos os mesmos tópicos de forma a localizar quais estavam presentes e quais estavam ausentes nos textos produzidos pelos estudantes. Entendemos que essas análises evidenciariam os conhecimentos que eles já possuem sobre a produção de texto desse gênero e aqueles que deveriam ser elencados como temas a serem ensinados. 


\subsection{Conteúdo temático}

Ao compararmos os textos produzidos e o texto de referência, foi possível perceber que os alunos parecem ter se apoiado mais em outras versões conhecidas do que propriamente na versão analisada, o que pode ser constatado em diferentes passagens do conto reproduzido, como na encomenda que a mãe solicita que a menina leve para a avó: uma cesta de pães, mas que, nas versões dos alunos, transforma-se em uma cesta de biscoito, de frutas ou de doces. Outro exemplo é a referência a um atalho tomado pelo lobo, que aparece em três dos seis textos analisados e não consta no texto tomado como referência.

A análise dos textos produzidos pelos alunos mostrou que todos recuperaram o tema principal, porém, em alguns casos, observamse lacunas nos enunciados que comprometeriam a compreensão do enredo se o leitor não o conhecesse. Detalharemos essa análise a seguir, no tópico 4.3 .

Os estudantes, talvez pela faixa etária e por terem um conhecimento textual muito ligado ao exercício da língua oral, não parecem perceber a necessidade de contar todo o enredo. Usam a escrita, conforme afirma Olson (1997), como um recurso mnemônico, como se fossem notas para evocar a memória.

Se a escrita é um simples recurso mnemônico, os seus signos não podem ser tomados como a representação adequada das crenças e intenções de quem os escreveu, capazes de representar essas crenças e intenções. 0 signo apenas lembra o sentido visado. Com efeito, na medida em que a escrita só preserva o léxico e a sintaxe, perdem-se então os demais aspectos não lexicais relativos à intenção com que se visou uma determinada audiência, isto é, a atitude do falante para com aquilo que foi dito, os quais precisam ser recuperados de outras fontes, tais como a lembrança do som histriônico da voz de quem falou ou o contexto. (OLSON, 1997, p. 198)

\subsection{Construção composicional}

Nos textos dos alunos, observamos também a presença (ou ausência) das fases da narrativa, tal como fizemos no texto de referência. Organizamos as reproduções em quadros, os quais serão apresentados a seguir: 
TEXTO 1

\begin{tabular}{|l|l|}
\hline \multirow{4}{*}{ 1. Fase da situação inicial } & $\begin{array}{l}\text { ERA UMA VEZ UMA MENINA CHAMADA CHAPEUZINHO } \\
\text { VERMELHO E UM DIA SUA MÃE DISSE CHAPEUZINHO } \\
\text { VERMELHO VAI LEVAR ESSE BISCOITO PARA SUA AVÓ ESTÁ } \\
\text { BOM MAMÃE E A CHAPEUZINHO FOI PARA O LADO }\end{array}$ \\
\hline 2. Fase da complicação & $\begin{array}{l}\text { E DE REPENTE O LOBO DISSE O QUE TEM NESSA CESTA TEM } \\
\text { BISCOITO }\end{array}$ \\
\hline 3. Fase das ações & $\begin{array}{l}\text { E O LOBO A SEGUIU E A CHAPEUZINHO FOI PELO LUGAR } \\
\text { A AVÓ E CHAPEUZINHO BATE NA PORTA E O LOBO DISSE } \\
\text { PODE ENTRAR E A CHAPEUZINHO FALOU NOSSA VOVÓ QUE } \\
\text { ORELHA GRANDE VOCÊ TEM SÃO PRA TE OUVIR MELHOR } \\
\text { NOSSA VOVÓ QUE OLHO GRANDE VOCÊ TEM VOVÓ SÃO PRA } \\
\text { TE VER MELHOR NETINHA NOSSA VOVÓ QUE DENTE GRANDE } \\
\text { VOCÊ TEM SÃO PRA TE DEVORAR E A CHAPEUZINHO FOI } \\
\text { DEVORADA }\end{array}$ \\
\hline 4. Fase da resolução & Fase da moral \\
\hline Fase da situação final & \\
\hline
\end{tabular}

Quadro 2 - Fases da narrativa no conto reescrito pelo aluno 1

\section{TEXTO 2}

\begin{tabular}{|l|l|}
\hline 1. Fase da situação inicial & $\begin{array}{l}\text { ERA UMA VEZ UMA MENINA CHAMADA CHAPEUZINHO } \\
\text { VERMELHO EM SUA CASA A MÃE MANDOU CHAPEUZINHO } \\
\text { VERMELHO IR LEVAR UMA CESTA DE FRUTAS E CHAPEUZINHO } \\
\text { VERMELHO }\end{array}$ \\
\hline 2. Fase da complicação & DE REPENTE O LOBO APARECE \\
\hline 3. Fase das ações & $\begin{array}{l}\text { E CORTA CAMINHO E CHEGA ANTES DE CHAPEUZINHO } \\
\text { VERMELHO E COME A VOVÓ E DEITA NA CAMA E FINGE SER A } \\
\text { VOVÓ E A CHAPEUZINHO VERMELHO FALA NOSSA VOVÓ QUE } \\
\text { BOCÃO É PRÁ TE COMER MELHOR }\end{array}$ \\
\hline 4. Fase da resolução & $\begin{array}{l}\text { E O CAÇADOR ABRIU A BARRIGA DO LOBO E NEM MACHUCOU } \\
\text { A VOVÓ }\end{array}$ \\
\hline 5. Fase da situação final & OI MINHA NETINHA \\
\hline Fase da moral & \\
\hline
\end{tabular}

Quadro 3 - Fases da narrativa no conto reescrito pelo aluno 2 


\section{TEXTO 3}

ERA UMA VEZ UMA MENINA QUE SE CHAMAVA CHAPEUZINHO VERMELHO UM DIA A VOVOZINHA DELA FICOU DOENTE CHAPEUZINHO VERMELHO VAI LEVAR ESSA CESTA DE DOCE

1. Fase da situação inicial PARA SUA VOVOZINHA CHAPEUZINHO NÃO CONVERSE COM ESTRANHOS NO CAMINHO E ELA DISSE SIM MAMÃE VOU LEVAR JÁ SUA MÃE DISSE SIM MAMÃE

NO MEIO DO CAMINHO ENCONTROU UM LOBO QUE HÁ MUITO

2. Fase da complicação TEMPO NÃO COMIA PERGUNTOU PARA CHAPEUZINHO O QUE TEM NESSA CESTA DOCES PARA MINHA AVÓ

ELE DISSE QUE CONHECIA UM CAMINHO MAIS PERTO E A MENINA FOI PELO CAMINHO MAIS LONGO E O LOBO FOI AO MAIS PERTO O LOBO CHEGOU A CASA DA VOVÓ PRIMEIRO E COMEU A VOVÓ TODINHA ELE DISFARÇOU DE VOVÓ CHAPEUZINHO CHEGOU A CASA DA VOVÓ E FALOU QUE

3. Fase das ações OLHOS GRANDES VOCÊ TEM É PRA TE ENXERGAR MELHOR QUE ORELHAS PONTUDAS QUE VOCÊ TEM SÃO PRA TE OUVIR MELHOR MINHA NETINHA MAS QUE NARIZ GRANDES VOCÊ TEM É PRA TE CHEIRAR MELHOR E QUE BOCA GRANDE É PRA TE COMER MELHOR E O LOBO COMEU A MENINA EM UMA BOCADA SÓ

\begin{tabular}{|l|l|}
\hline 4. Fase da resolução & $\begin{array}{l}\text { OS AMIGUINHOS DELA CHAMARAM OS CAÇADORES PARA } \\
\text { SALVAR AS DUAS OS CAÇADORES CORRERAM E CORTARAM } \\
\text { A BARRIGA DO LOBO E TIRARAM AS DUAS DA BARRIGA DO } \\
\text { LOBO E COMEMORARAM }\end{array}$ \\
\hline 5. Fase da situação final & \\
\hline 6. Fase da moral & \\
\hline
\end{tabular}

Quadro 4 - Fases da narrativa no conto reescrito pelo aluno 3

\section{TEXTO 4}

\begin{tabular}{|l|l|}
\hline 1. Fase da situação inicial & \\
\hline \multirow{3}{*}{ 2. Fase da complicação } & $\begin{array}{l}\text { ELA VIU ALGUMAS FLORES E SE PERDEU NA FLORESTA } \\
\text { E O LOBO APARECEU NA FRENTE DA MENINA E FOI } \\
\text { CONVERSANDO COM A MENINA }\end{array}$ \\
\hline \multirow{5}{*}{ 3. Fase das ações } & ELE DISSE BOM EU VOU EMBORA E DEIXO VOCÊ NA TRILHA \\
& DE VOLTA PARA A CASA DA VOVÓ E O LOBO ENGANOU A \\
& MENINA E PEGOU UM ATALHO PARA CHEGAR NA CASA DA \\
& DA VOVIMEIRO DA MENINA E QUANDO CHEGOU NA CASA \\
& MENINA FALOU QUE OLHOS GRANDES VOCÊ TEM VOVÓ E \\
& QUE ORELHAS GRANDES VOCÊ TEM VOVÓ E QUE GRANDES \\
& DENTES GRANDES VOCÊ TEM VOVÓ É PARA COMER VOCÊ \\
\hline
\end{tabular}


continua...

\begin{tabular}{|l|l|}
\hline 4. Fase da resolução & $\begin{array}{l}\text { UM CAÇADOR VIU O LOBO DEBAIXO DA ÁRVORE E ABRIU A } \\
\text { BARRIGA DO LOBO E FECHOU A BARRIGA DO LOBO }\end{array}$ \\
\hline 5. Fase da situação final & \\
\hline 6. Fase da moral & \\
\hline
\end{tabular}

Quadro 5 - Fases da narrativa no conto reescrito pelo aluno 4

\section{TEXTO 5}

\begin{tabular}{|c|c|}
\hline 1. Fase da situação inicial & $\begin{array}{l}\text { ERA UMA VEZ UMA MENINA QUE SE USAVA } \\
\text { UM CAPUZ E UM CHAPEU VERMELHO E } \\
\text { ASSIM ELA COMEÇOU A SER CHAMADA DE } \\
\text { CHAPEUZINHO VERMELHO. UM DIA SUA MÃE } \\
\text { A CHAMOU CHAPEUZINHO VERMELHO LEVE } \\
\text { ESSES DOCES PARA SUA VOVÓ ELA ESTÁ } \\
\text { DOENTE MAS NÃO VÁ PELA FLORESTA TEM } \\
\text { UM LOBO POR LÁ ESTÁ BOM MAMÃE. E ASSIM } \\
\text { ELA SE DISTRAIA COM AS FLORES E ELA } \\
\text { ENTROU NA FLORESTA }\end{array}$ \\
\hline 2. Fase da complicação & $\begin{array}{l}\text { E VIU O LOBO E ELE DISSE AONDE VAI MENINA VOU LEVAR } \\
\text { ESSES DOCES PARA MINHA VOVÓ ELA ESTÁ DOENTE EU } \\
\text { CONHEÇO UM ATALHO }\end{array}$ \\
\hline 3. Fase das ações & $\begin{array}{l}\text { E A MENINA FOI ALI. E O LOBO PEGOU UM ATALHO E CHEGOU } \\
\text { NA CASA DA VOVÓ E SE VESTIU ELA CHEGOU DEPOIS E } \\
\text { BATEU NA PORTA E O LOBO DISSE PODE ENTRAR A MENINA } \\
\text { FEZ AS PERGUNTAS VOVÓ POR QUE ESSAS ORELHAS TÃO } \\
\text { GRANDES É PRA TE ESCUTAR MELHOR E POR QUE ESSES } \\
\text { OLHOS TÃO GRANDES É PARA TE VER MELHOR SÃO PRA TE } \\
\text { OUVIR MELHOR MINHA NETINHA E POR QUE ESSE NARIZ TÃO } \\
\text { GRANDE É PARA TE CHEIRAR MELHOR E POR QUE ESSA BOCA } \\
\text { TÃO GRANDE É PARA TE COMER E SAI CORRENDO ATRAS DA } \\
\text { MENINA E ELA FICOU GRITANDO SOCORRO }\end{array}$ \\
\hline 4. Fase da resolução & $\begin{array}{l}\text { E UM GRUPO DE CAÇADORES QUE ESTÁ PERTO OUVIU OS } \\
\text { GRITOS E CORREU E COM O FACÃO CORTOU A BARRIGA DO } \\
\text { LOBO E TIROU A VOVÓ DE DENTRO DA BARRIGA }\end{array}$ \\
\hline 5. Fase da situação final & E ELAS SE ABRAÇARAM POR UM BOM TEMPO E FIM \\
\hline 6. Fase da moral & \\
\hline
\end{tabular}

Quadro 6 - Fases da narrativa no conto reescrito pelo aluno 5 


\begin{tabular}{|l|l|}
\hline \multicolumn{2}{|c|}{ TEXTO 6 } \\
\hline 1. Fase da situação inicial & $\begin{array}{l}\text { ERA UMA VEZ UMA MENINA CHAMADA CHAPEUZINHO } \\
\text { VERMELHO SUA MÃE MANDOU A ELA A LEVAR A CESTA PARA } \\
\text { A VOVOZINHA DELA E ASSIM FOI }\end{array}$ \\
\hline 2. Fase da complicação & LÁ ENCONTROU UM LOBO MUITO MALVADO \\
\hline 3. Fase das ações & $\begin{array}{l}\text { ELE PEGOU UM ATALHO E CHEGOU PRIMEIRO QUANDO ELE } \\
\text { CHEGOU ELE COMEU A VOVOZINHA E VESTIU A ROUPA E } \\
\text { DEITOU NA CAMA A MENINA CHEGOU E O LOBO COMEU A } \\
\text { MENINA }\end{array}$ \\
\hline 4. Fase da resolução & $\begin{array}{l}\text { DEPOIS OS CAÇADORES CORTARAM A BARRIGA DO LOBO E } \\
\text { TIROU A VOVOZINHA }\end{array}$ \\
\hline 5. Fase da situação final & ENTÃO A VOVÓ ESTÁ SALVA \\
\hline 6. Fase da moral & \\
\hline
\end{tabular}

Quadro 7 - Fases da narrativa no conto reescrito pelo aluno 6

Como no texto de referência, as sequências narrativas alinhavam a história nas reproduções dos alunos. Com maior ou menor extensão ou com maior ou menor complexidade, essas sequências estão presentes em todos os textos e são responsáveis pelo desenrolar da história.

A observação dos quadros de 2 a 7 permite perceber que os alunos conhecem os fatos, respeitando, na maioria das vezes, a ordem cronológica em que acontecem, mas ainda apresentam um conhecimento frágil sobre como transformá-los em uma narrativa escrita. Desconhecem, por exemplo, a necessidade de evidenciar o desequilíbrio causado pelo aparecimento do lobo na fase da complicação, por meio da qualificação das personagens. Enquanto no texto de referência o antagonista é introduzido como tendo "dois terríveis olhos" e "um vozeirão" e a menina é recuperada como "garota assustada", no texto 4 (quadro 5), o encontro entre protagonista e antagonista é descrito da seguinte forma: "o lobo apareceu na frente da menina e foi conversando com a menina".

Com exceção do texto 4 (quadro 5), todos se iniciam com a expressão "Era uma vez", abertura típica dos contos maravilhosos, o que demonstra certa familiarização dos estudantes com o gênero. E afora o texto 6 (quadro 7), nos demais há a introdução de sequências dialogais, principalmente entre a falsa avó e a netinha, passagem crucial para o encerramento da história. De certa forma, tal ocorrência era esperada, uma vez que nesses trechos a sequência dialogal deixa de exercer um papel secundário na trama. 
Apesar de o diálogo entre as personagens estar presente nos textos de praticamente todos os alunos, não há o emprego de pontuação de discurso direto.

0 uso dos verbos dicendi para introduzir a fala dos personagens é inconsistente, estando presente em apenas alguns casos, como no texto 1 (quadro 2): "Era uma vez uma menina chamada chapeuzinho vermelho e um dia sua mãe disse Chapeuzinho Vermelho vai levar esse biscoito para sua avó [ $\emptyset]$ está bom mamãe". Não foram encontradas sequências descritivas nas reproduções realizadas. Há apenas a descrição da personagem no texto 5 (quadro 6): "Era uma vez uma menina que se usava um chapéu vermelho e assim ela começou a ser chamada de Chapeuzinho Vermelho".

\subsection{Recursos estilísticos}

Da mesma forma como fizemos no texto tomado como referência, identificamos as cadeias coesivas da personagem e de seu antagonista na reprodução dos alunos. Verificamos que na maioria dos textos foi utilizada a repetição para a referenciação, como no exemplo a seguir: "Era uma vez uma menina chamada Chapeuzinho Vermelho e um dia sua mãe disse Chapeuzinho Vermelho vai levar esses biscoitos para sua avó".

Apenas nos textos 3, 5 e 6 (quadros 4, 6 e 7) houve substituição por pronomes e/ou expressões nominais: "sua mãe", referindose à menina (texto 5, quadro 6); "ele disse", referindo-se ao lobo (texto 3, quadro 4). No texto 5 (quadro 6), há o uso mais sofisticado do pronome oblíquo - "sua mãe a chamou" -, o que pode demonstrar certa familiaridade com o gênero em sua forma escrita. Houve também, em alguns casos, a recuperação da personagem por meio de expressões nominais, por exemplo em "comeu a menina em uma bocada só", no texto 3 (quadro 4).

É possível notar também a utilização de diferentes tempos verbais, na maior parte das vezes marcando corretamente 0 primeiro e o segundo plano da narrativa, como no seguinte excerto: "Era uma vez uma menina chamada Chapeuzinho Vermelho. Sua mãe mandou ela levar a cestinha para a vovozinha dela e assim foi".

Observamos o emprego incorreto de tempos do mundo comentado nos trechos em que deveriam ter sido utilizados tempos verbais da narrativa: "de repente o lobo aparece e corta 
caminho e chega antes de Chapeuzinho Vermelho e come a vovó e deita na cama e finge ser a vovó". É possível que esse equívoco tenha se dado devido à tentativa de imprimir um clima de ação e suspense, de engajamento do leitor ao texto; conforme afirma Koch (1991, p. 53), "os tempos do comentário conduzem o ouvinte a uma atitude receptiva, tensa, engajada, atenta".

Quanto aos mecanismos de sequenciação frástica, observamos que, na maior parte das reproduções, o encadeamento se dá por justaposição de frases ou pela reiteração do conectivo e, como ilustram os seguintes trechos, respectivamente: "O lobo comeu a menina em uma bocada só. [ $\emptyset]$ Os amiguinhos dela chamaram os caçadores para salvar as duas"; " $e$ o lobo enganou a menina $e$ pegou um atalho para chegar na casa da vovó primeiro da menina e quando $[\ldots] "$ ".

Em muitos textos, essa forma de sequenciação provocou saltos temáticos que resultariam na não compreensão do conto ou de partes dele caso o leitor desconhecesse o enredo. Isso é observado em: "a mãe mandou Chapeuzinho Vermelho ir levar uma cesta de frutas [Onde? Para quem?] e Chapeuzinho Vermelho [Fez o quê? Disse o quê?] de repente o lobo aparece [Onde?]"; "e quando chegou na casa da vovó [Quem chegou?] e comeu a vovó e disfarçado de vovó a menina falou [A menina estava lá enquanto 'ele' comeu a avó? Quando ela chegou?]".

Não foram encontrados articuladores próprios da oralidade, tais como daí e né, o que pode indicar que esses alunos já têm o conhecimento de que esse tipo de articulador não é apropriado para o texto escrito.

Os articuladores textuais indicadores de tempo e espaço estiveram presentes em todos os textos, porém, ainda de forma muito inconsistente. 0 número de ocorrências de marcadores temporais variou entre uma e três em cada reprodução. A ausência desses marcadores só não interferiu na inteligibilidade do texto devido ao enredo ser conhecido, conforme pode ser observado no exemplo a seguir: "ele comeu a vovozinha e vestiu a roupa e deitou na cama a menina chegou e o lobo comeu a menina".

\section{A leitura dos professores}

Entregamos o conjunto dos textos selecionados e analisados a doze professores de escolas públicas e particulares, e solicitamos que, após a leitura e a análise do material, respondessem a duas questões: 
a) Imagine que os textos desses alunos representem sua classe de $3^{\circ}$ ano. Que conhecimentos esses alunos já possuem sobre produção de contos maravilhosos?

b) Quais conteúdos de produção de texto você selecionaria para trabalhar com essa classe?

Antes de entregarmos os textos aos professores, optamos por transcrevê-los, fazendo a correção dos erros ortográficos e da segmentação em palavras. Essa opção objetivou desviar o olhar dos professores em relação aos padrões de escrita e, dessa forma, direcioná-lo para outros aspectos. Nossa intenção foi observar para onde dirigiriam o foco de sua análise, uma vez que os aspectos ortográficos, que saltam aos olhos de todo professor, estariam dissimulados.

Categorizamos as respostas e as organizamos utilizando os mesmos critérios, nos quais pautamos a análise do texto utilizado como referência e as reproduções dos alunos.

\subsection{0 que os professores pensam que seus alunos sabem}

Nosso primeiro movimento foi identificar quantos professores mencionaram cada um desses tópicos e depois transcrever o que haviam referido, buscando conservar, ao máximo, os termos e as expressões utilizadas por eles.

\begin{tabular}{|c|c|}
\hline \multicolumn{2}{|c|}{ CONTEÚDO TEMÁTICO } \\
\hline Número de respostas & Percentual do total \\
\hline 8 & $67 \%$ \\
\hline
\end{tabular}

Quadro 8 - Respostas dos professores à $1^{\text {a }}$ questão (recorte: conteúdo temático)

Apesar de oito professores terem feito referência a aspectos relacionados ao conteúdo temático, nenhum deles mencionou as lacunas e os saltos temáticos que produziriam incoerências caso não se tratasse de um conto tão conhecido.

De forma geral, eles pareceram não identificar o quanto seus alunos ainda estão baseados na oralidade, situação comunicativa na qual não é necessário contar tudo, uma vez que os interlocutores podem esclarecer eventuais lacunas ou dúvidas. 
CONSTRUÇÃO COMPOSICIONAL

\begin{tabular}{|c|c|}
\hline Número de respostas & Percentual do total \\
\hline 3 & $25 \%$ \\
\hline
\end{tabular}

Quadro 9 - Número de respostas dos professores à $1^{a}$ questão (recorte: construção composicional)

Como se pode notar no quadro 9, apenas a quarta parte dos professores pesquisados apontou conhecimentos relativos à estrutura composicional. Mesmo quando identificam início, meio e fim na organização interna como gênero, eles não observam que a forma como os alunos escrevem não traduz integralmente esse conteúdo.

\begin{tabular}{|c|c|}
\hline \multicolumn{2}{|c|}{ RECURSOS ESTILÍSTICOS } \\
\hline Número de respostas & Percentual do total \\
\hline 5 & $42 \%$ \\
\hline
\end{tabular}

Quadro 10 - Respostas dos professores à $1^{\mathrm{a}}$ questão (recorte: recursos estilísticos)

Quase a metade dos professores apontou aspectos relacionados aos recursos estilísticos, mesmo não utilizando termos específicos. Ao afirmarem que os "textos apresentam coesão e coerência parciais", é possível que possam estar se referindo aos saltos temáticos que alguns alunos apresentaram em seus textos.

Pode-se localizar aí possíveis tópicos de formação na área da linguística textual, de modo a repertoriar os professores e explicitar os mecanismos e recursos estilísticos que estão presentes nos textos e que devem ser compreendidos por aqueles que estão aprendendo a produzir textos de diferentes gêneros.

Apesar de as reproduções dos alunos terem sido transcritas com os erros ortográficos corrigidos e sem problemas de segmentação, aspectos relativos aos padrões da escrita foram observados por todos os professores, como se observa no quadro seguinte:

\begin{tabular}{|c|c|}
\hline \multicolumn{2}{|c|}{ PADRÕES DA ESCRITA } \\
\hline Número de respostas & Percentual do total \\
\hline 12 & $100 \%$ \\
\hline
\end{tabular}

Quadro 11 - Respostas dos professores à $1^{\text {a }}$ questão (recorte: padrões da escrita) 
É muito interessante que esse tenha sido o único elemento apontado por todos os professores. Aspectos relacionados aos padrões de escrita, por serem visíveis ao primeiro olhar e, aparentemente, mais fáceis de corrigir e ensinar, parecem ser aqueles que se colocam em primeiro plano para o professor.

\subsection{0 que os professores pensam que seus alunos devem aprender}

A segunda pergunta a que os professores deveriam responder era a seguinte: Quais conteúdos de produção de texto você selecionaria para trabalhar com essa classe? Procuramos manter a mesma categorização em quadros para que pudéssemos estabelecer parâmetros de comparação entre as respostas dadas às duas perguntas.

\begin{tabular}{|c|c|}
\hline \multicolumn{2}{|c|}{ CONTEÚDO TEMÁTICO } \\
\hline Número de respostas & Percentual do total \\
\hline 0 & $0 \%$ \\
\hline
\end{tabular}

Quadro 12 - Respostas dos professores à $2^{\text {a }}$ questão (recorte: conteúdo temático)

De certa forma, a ausência de respostas relacionadas a esse tópico era esperada, uma vez que oito dos doze professores haviam respondido, na primeira pergunta, que os alunos "conheciam a história" e "sabiam a sequência dos fatos", o que é correto, conforme já afirmamos.

Apesar de os professores fazerem uma leitura precisa, faltaIhes a consciência de que os alunos ainda não dominam a representação do texto escrito como um texto autônomo que prescinde da presença do interlocutor.

\begin{tabular}{|c|c|}
\hline \multicolumn{2}{|c|}{ CONSTRUÇÃO COMPOSICIONAL } \\
\hline Número de respostas & Percentual do total \\
\hline 5 & $42 \%$ \\
\hline
\end{tabular}

Quadro 13 - Respostas dos professores à $2^{\text {a }}$ questão (recorte: construção composicional)

Enquanto três professores identificaram aspectos relacionados à construção composicional como conhecimento que os alunos já possuíam, cinco - ou seja, quase o dobro - indicaram esses 
aspectos como temas de ensino. Esse aumento pode parecer lógico a princípio, mas uma análise qualitativa das respostas apontou contradições. Na resposta à primeira pergunta, um professor afirmou que os alunos conheciam o gênero; porém, ao responder à segunda pergunta, o mesmo professor elencou "retomar as características do gênero" como conteúdo de ensino.

Nesse tópico, cabe também a ressalva de que parece faltar aos professores conhecimentos técnicos para expressar suas observações.

\begin{tabular}{|c|c|}
\hline \multicolumn{2}{|c|}{ RECURSOS ESTILÍSTICOS } \\
\hline Número de respostas & Percentual do total \\
\hline 6 & $50 \%$ \\
\hline
\end{tabular}

Quadro 14 - Respostas dos professores à $2^{\text {a }}$ questão (recorte: recursos estilísticos)

No que concerne aos recursos estilísticos, praticamente o mesmo número de professores identifica aspectos relacionados ao conhecimento dos alunos (cinco professores) e a temas de ensino (seis professores). Assim como ocorreu na primeira pergunta, os professores fazem referência a conteúdos relacionados a recursos estilísticos como coerência e coesão, mas o fazem ainda de forma vaga, possivelmente porque não dominam a linguagem técnica.

Também como na primeira questão, vários professores fizeram referência aos padrões da escrita, agora como conteúdos a serem ensinados, conforme demonstra o a seguir:

\begin{tabular}{|c|c|}
\hline \multicolumn{2}{|c|}{ PADRÕES DA ESCRITA } \\
\hline Número de respostas & Percentual do total \\
\hline 10 & $83 \%$ \\
\hline
\end{tabular}

Quadro 15 - Respostas dos professores à $2^{\text {a }}$ questão (recorte: padrões da escrita)

Tal como se pode observar, dez dos doze professores selecionaram conteúdos relacionados aos padrões da escrita para o ensino. Deve-se destacar aqui que dois professores não selecionaram conteúdos de ensino em nenhum dos tópicos utilizados na análise. 


\subsection{Conclusões}

Ao iniciarmos essa pesquisa, tínhamos algumas questões, entre elas as que fizemos aos professores: Que conhecimentos os alunos já possuem sobre produção de textos? E que conteúdos deveriam aprender? Partíamos da suposição de que os alunos já sabiam muitas coisas sobre produção de texto, mas, obviamente, ainda tinham muito a aprender.

Também supúnhamos que os professores identificavam alguns desses saberes, mas ainda não tinham a clara representação de quais conteúdos precisariam trabalhar para consolidar a alfabetização e garantir que seus alunos seguissem aprendendo a produzir textos.

Nossas suposições foram confirmadas, pelo menos parcialmente. Ao terminarem seu processo de alfabetização, os alunos realmente demonstraram ter adquirido alguns conhecimentos sobre a produção escrita, sendo capazes de reproduzir o conto, compreender os fatos principais do enredo e reconhecer que não deveriam utilizar os articuladores da linguagem oral.

Eles ainda necessitam, porém, aprender que a escrita pressupõe um interlocutor ausente e que isso implica prever possíveis dúvidas e preencher lacunas que não poderiam ser preenchidas somente pelo leitor. Devem aprender a coordenar os diferentes processos envolvidos no percurso da construção da autoria, tais como o contexto de produção e a memória de curto e longo prazo para gerenciar os processos de escrita, planejamento, tradução e revisão (FORTUNATO, 2009).

Com relação aos professores, ficou evidente a necessidade de uma formação específica quanto a temas relacionados à língua e à construção dos processos de escrita. Suas representações sobre os conteúdos a serem ensinados aos alunos são muito amplas e pouco precisas. Ainda, por parte de alguns, percebe-se o equívoco de que basta "colocar os alunos para escrever" para que escrevam.

A pesquisa deixou mais evidente o que já percebíamos empiricamente, ou seja, a importância de que os docentes, principalmente os chamados polivalentes, que lecionam nas séries iniciais do ensino fundamental, recebam formação específica acerca de temas da linguística. Todos os tópicos aqui apontados como necessários ao aprendizado dos alunos só poderão ser eficientemente ensinados por um professor que tenha, ao 
menos, alguns conhecimentos sobre a língua e sobre como ela se estrutura, conhecimentos estes que não são oferecidos na formação inicial do professor e que, portanto, devem ser pauta de cursos e ações de formação.

\section{REFERÊNCIAS}

BAKHTIN, Mikhail. Estética da criação verbal. Tradução Paulo Bezerra. São Paulo: Martins Fontes, 1997.

BRAIT, Beth (Org.). Bakhtin: conceitos-chave. São Paulo: Contexto, 2005.

BRONCKART, Jean-Paul. Atividade de linguagem, textos e discursos: por um interacionismo sócio-discursivo. São Paulo: EDUC, 2007.

FERREIRO, Emilia; TEBEROSKY, Ana. Psicogênese da língua escrita. Porto Alegre: Artes Médicas, 1985.

FORTUNATO, Márcia Vescovi. Autoria e aprendizagem da escrita. Tese (Doutorado em Educação) - Faculdade de Educação, Universidade de São Paulo, São Paulo, 2009.

GÓIS, Antônio. Estudo aponta que aluno da rede pública já chega pior à $1^{a}$ série. Folha de S. Paulo, São Paulo, 11 jan. 2010. Disponível em <http://www1.folha.uol.com.br/folha/ educacao/ult305u677350.shtml>. Acesso em: 15 ago. 2010.

INSTITUTO PAULO MONTENEGRO. INAF Brasil 2009: Indicador de alfabetismo funcional: principais resultados. São Paulo, 2010. Disponível em: <http://www.ipm.org.br/download/ inaf_brasil_2009_relatorio_divulgacao_revisto_fev-11_ vFinal.pdf>. Acesso em: 12 ago. 2010.

KOCH, Ingedore Villaça. A coesão textual. São Paulo: Contexto, 1991.

KOCH, Ingedore Villaça; ELIAS, Vanda Maria. Ler e escrever: estratégias de produção textual. São Paulo: Contexto, 2009.

MARCUSCHI, Luiz Antônio. Gêneros textuais: definição e funcionalidade. In: DIONISIO, Angela Paiva et al. (Orgs.). Gêneros textuais \& ensino. Rio de Janeiro: Lucerna, 2002. p. $19-38$. 
NÓBREGA, Maria José. Paráfrase, autoria e processos de assimilação da palavra do outro. Tese (Mestrado em Letras) - Faculdade de Filosofia, Letras e Ciências Humanas, Universidade de São Paulo, São Paulo, 2000.

OLSON, David R. Uma história do discurso escrito: da mnemônica às representações. In: 0 mundo do papel: as implicações conceituais e cognitivas da leitura e da escrita. São Paulo: Ática, 1997.

SOARES, Magda. Letramento: um tema em três gêneros. Belo Horizonte: Editora Autêntica, 2000.

Recebido em: 19/02/2013 Aprovado em: 04/04/2013 